J. Amer. Soc. Hort. Sci. 116(4):737-739. 1991.

\title{
Inheritance of Aconitase, Shikimate Dehydrogenase, and Phosphoglucose Isomerase in Guayule
}

\author{
A. Hashemi ${ }^{1}$, A. Estilai ${ }^{2}$, and B. Ehdaie ${ }^{1}$ \\ Department of Botany and Plant Sciences, University of California, Riverside, CA 92521
}

Additional index words. Parthenium argentatum

Abstract. Starch gel electrophoresis was carried out to investigate inheritance of aconitase (ACO), shikimate dehydrogenase $(\mathrm{SKDH})$, and phosphoglucose isomerase (PGI) in guayule (Parthenium argentatum Gray). Self-incompatibility of diploid guayule $(2 n=36)$, prevented production of $\mathrm{F}_{2}$ generations. A series of crosses was made for segregation analysis. The enzyme ACO showed two zones of activity-one monomorphic and the other polymorphic, representing one locus with two alleles. SKDH was found to be coded by two loci with three alleles at each locus. Four zones of activity were found for PGI. PGI-1, the fastest zone, was poorly resolved and appeared variable. Segregation data indicated that PGI-2 is monogenic and controlled by five codominant alleles. Poor resolution of PGI4 made it impossible to determine whether PGI-3 was the product of a separate locus or resulted from intergenic cross dimerization between PGI-2 and PGI-4. The dimeric characteristic of PGI-2 and the monomeric structure of SKDH and ACO-1 in guayule agreed with the protein structures previously reported for these enzymes in other plant species. The isozyme variation of this investigation maybe used in a breeding program to identify sexual and maternal type progenies of facultative apomictic guayule plants at the early seedling stage.

Guayule, a rubber-producing shrub of the Chihuahuan desert, is a potential industrial crop for arid and semiarid regions. In addition to rubber, guayule produces significant amounts of resin, a by-product that can be used as a wood preservative, a fuel source, and a rubber additive (Schloman, 1986). Due to low rubber yield, guayule has not yet been commercialized. However, the high rubber-yielding selections developed by breeding programs (Estilai, 1986; Thompson and Ray, 1989) may bring about commercialization in the near future.

Guayule plants have 36, 54, 72, and higher chromosome numbers. Diploid plants $(2 n=36)$ are sexual and self-incompatible (Gerstel, 1950; Gerstel and Mishanec, 1950; Powers, 1945). Polyploids, however, reproduce by facultative apomixis (Esau, 1944), producing progenies derived from either maternal tissue or fertilized eggs. Morphological and biochemical markers are needed to identify the two progeny types at the seedling stage. So far, only one morphological marker (purple flower), which can be observed only at flowering, has been identified and genetically analyzed (Estilai, 1984). Potential linkage between biochemical markers and desirable traits may allow early screening of many seedlings, as has been demonstrated in pea (Weeden et al., 1984) and tomato (Tanksley et al., 1982). Isozyme research in guayule is limited to two studies. Zaiger et al. (1984) used isozymes to demonstrate variation in a sexual diploid germplasm population. Estilai et al. (1990) showed a uniform electrophoretic pattern in two polyploid apomictic germplasms. To the best of our knowledge, no isozyme inheritance study has been reported in guayule.

\footnotetext{
Received for publication 13 Aug. 1990. Research was supported in part by USDA Grant 89-38200-4375 and USDA/CSRS Cooperative Agreement no. 89COOP-1-4949. Any opinion and conclusions or recommendations expressed in this publication are those of the authors and do not necessarily reflect the views of the USDA. References to commercial products or services are made with the understanding that no discrimination is intended and no endorsement is made by the USDA or the Univ. of California. The cost of publishing this paper was defrayed in part by the payment of page charges. Under postal regulations, this paper therefore must be hereby marked advertisement solely to indicate this fact.

'Postgraduate Geneticist.

${ }^{2}$ Associate Research Agronomist.
}

We report the inheritance of aconitase (EC 4.2.1.3; ACO), shikimate dehydrogenase (EC 1.1.1.25; SKDH), and phosphoglucose isomerase (EC 5.3.1.9; PGI) in diploid guayule.

\section{Materials and Methods}

A total of 50 glasshouse-grown, diploid guayule plants, derived from the only available diploid germplasm, Cal-3 (Tysdal et al., 1983), were initially assayed for isocitric dehydrogenase (EC 1.1.1.42; IDH), malate dehydrogenase (EC 1.1.1.37; MDH), SKDH, PGI, triosephosphate isomerase (EC 5.3.1.1; TPI), and ACO. IDH, MDH, and TPI were eliminated from further study because they showed monomorphic patterns. Hybrid progenies between enzyme variants were generated by controlled crosses (Table 1) following the procedures described by Hashemi et al. (1986). Young leaf samples were ground in Plexiglass wells with a glass rod using $0.1 \mathrm{ml}$ of refrigerated (4C) extraction buffer. The extraction buffer consisted of $30 \mathrm{mg}$ DL-dithiothreitol (DTT), $3 \mathrm{~g}$ polyvinylpyrrolidone (PVP-40), and four drops of 2-mercaptoethanol to which $20 \mathrm{ml} 0.1 \mathrm{M}$ Tris $\cdot \mathrm{HCl}(\mathrm{pH} \mathrm{8.0)}$ was added. The electrophoretic buffer and the staining recipes for IDH, MDH, SKDH, PGI, and TPI have been described. (Estilai et al., 1990); the recipe for ACO staining was reported in Garvin (1987). The gel used for ACO, PGI, and SKDH consisted of $9.6 \%$ starch and $0.009 \mathrm{M}$ L-histidine, titrated to $\mathrm{pH} 6.0$ with citric acid. The electrode buffer was $0.065 \mathrm{M} \mathrm{L-histidine,} \mathrm{titrated} \mathrm{to} \mathrm{pH} 6.0$ with citric acid (Ellstrand, 1984). The extracts were absorbed onto filter paper wicks that were loaded into a transverse slice cut in the starch gels. Electrophoresis was conducted at 4C, $150 \mathrm{~V}$ and $25 \mathrm{MA}$. After $6 \mathrm{~h}$, gels were sliced and stained.

Designation of allozymes was based on the migration distance of the most common allele at each locus, which was assigned the number 100. Other alleles were identified numerically as to the percentage of migration compared with the 100 allele.

Inheritance analyses were carried out using a $\mathrm{x}^{2}$ goodness-offit test assuming monogenic and codominant expression of alleles at a single locus (Table 1).

\section{Results and Discussion}

Enzymes ACO, SKDH, and PGI showed allozyme variation at four loci, the inheritance of which are discussed below. 
Aconitase. ACO showed two zones of activity, polymorphic at the fast zone, ACO-1, and monomorphic at the slow zone, ACO-2. At ACO-1, two bands with different mobility (representing alleles 100 and 82) were identified (Figs. 1A and 2). Hybrid progenies between ACO-1 variants showed the ,two parental bands with no intermediate heterodimeric band (Table 1). Segregation analyses of ACO-1 confirmed the hypothesis that one locus controls the fast zone. In guayule, ACO-1 allozymes are monomeric, similar to those observed for other plant spe- ties, such as Festuca ovina (Weibull et al., 1988) and Phaseolus acutifolius (Garvin et al., 1989).

Shikimate dehydrogenase. SKDH showed two zones of activity, designated SKDH-1 and SKDH-2, for the fast- and the slow-migrating zones, respectively (Figs. 1 and 2). At zone 1, three bands representing three alleles, fast (allele 105), intermediate (allele 100), and slow (allele 94), were recognized. Three alleles $(100,88$, and 76) were also found for the SKDH2 locus. Crosses between homozygous plants with 105/105 and

Table 1. Segregation of three isozymes in diploid guayule

\begin{tabular}{llccccc}
\hline \hline $\begin{array}{l}\text { Isozyme } \\
\text { (locus) }\end{array}$ & $\begin{array}{l}\text { Parental } \\
\text { genotypes }\end{array}$ & \multicolumn{1}{c}{$\begin{array}{c}\text { Frequencies of } \\
\text { observed genotypes }\end{array}$} & Total & $\begin{array}{c}\text { Expected } \\
\text { ratio }\end{array}$ & $\chi^{2}$ & $P$ \\
\hline ACO-1 & $\frac{82}{82} \times \frac{100}{82}$ & $26 \frac{100}{82}: 19 \frac{82}{82}$ & 45 & $1: 1$ & 1.09 & $0.5>P>0.1$ \\
SKDH-1 & $\frac{100}{94} \times \frac{100}{100}$ & $27 \frac{100}{100}: 34 \frac{100}{94}$ & 61 & $1: 1$ & 0.803 & $0.5>P>0.1$ \\
SKDH-2 & $\frac{100}{100} \times \frac{100}{76}$ & $20 \frac{100}{100}: 24 \frac{100}{76}$ & 44 & $1: 1$ & $0.3640 .9>P>0.5$ \\
PGI-2 & $\frac{121}{114} \times \frac{106}{100}$ & $15 \frac{121}{106}: 18 \frac{121}{100}: 15 \frac{114}{106}: 19 \frac{114}{100}$ & 64 & $1: 1: 1: 1$ & $0.7610 .9>P>0.5$ \\
& $\frac{121}{106} \times \frac{114}{106}$ & $20 \frac{121}{114}: 15 \frac{121}{106}: 11 \frac{114}{106}: 10 \frac{106}{106}: 56$ & $1: 1: 1: 1$ & 4.427 & $0.5>P>0.1$ \\
\hline
\end{tabular}

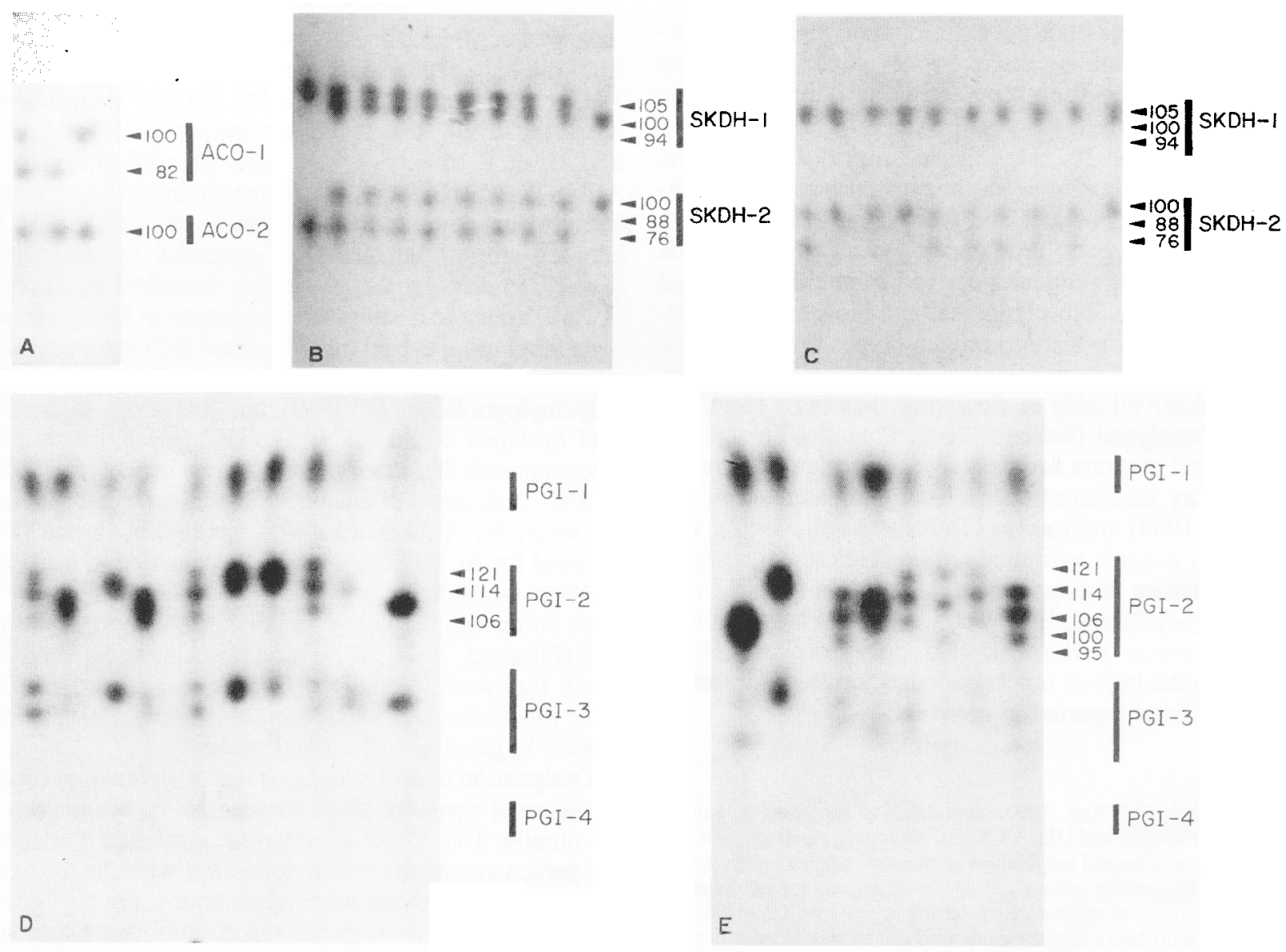

Fig. 1. Expression of guayule isozymes. (A) ACO variants and their hybrid (left). (B) SKDH, homozygous parents (far left and far right) and their hybrids (middle) at the fast and slow zones. (C) Segregating progenies at SKDH-2, putative genotypes, from left to right, Parent (100/ 76), progenies $(100 / 100,100 / 100,100 / 100,100 / 76,100 / 76,100 / 76,100 / 76,100 / 76)$, and parent (100/100). (D, E) PGI-2 segregation. (D) From left to right, parents (121/106 and 114/106) and their hybrids $(121 / 114,114 / 106,121 / 106,121 / 114,121 / 114,121 / 106,114 / 106$, and 106/106). (E) Parents (106/100 and 121/114) and their hybrids (114/100, 114/106, 121/106, 121/100, 121/106, and 114/100). 


\begin{tabular}{|c|c|c|c|c|}
\hline $\begin{array}{c}A C O-1 \\
\frac{82}{82} \frac{100}{82} \frac{100}{100} \\
-- \\
-- \\
-- \\
\frac{100}{100} \frac{100}{100} \frac{100}{100}\end{array}$ & $\begin{array}{c}- \\
-\frac{76}{76} \frac{100}{76} \frac{100}{100}\end{array}$ & $\begin{array}{l}\text { SKDH-1 } \\
\frac{105}{105} \frac{105}{105} \frac{105}{105} \frac{105}{105} \\
-\overline{-}-- \\
\overline{\frac{100}{76}} \frac{100}{100} \frac{100}{76} \frac{100}{100}\end{array}$ & $\begin{array}{c}\text { PGH-2 } \\
\frac{121}{106} \frac{114}{106} \frac{121}{114} \frac{121}{106} \frac{114}{106} \\
=\bar{z}=\overline{=} \\
=\bar{z}\end{array}$ & $\begin{array}{c}\text { PGI-2 } \\
\frac{121}{114} \frac{121}{106} \frac{121}{100} \frac{114}{100} \frac{114}{100} \frac{106}{100} \\
\equiv=- \\
=-\overline{-}=\end{array}$ \\
\hline $\mathrm{ACO}_{-2}$ & SKDH-2 & SKDH-2 & & \\
\hline
\end{tabular}

Fig. 2. Schematic illustration showing isozyme patterns for ACO-1, ACO-2; SKDH-1, SKDH-2, and PGI-2 in guayule.

100/100 genotypes at the SKDH-1 zone produced 20 progenies, all of which showed the hybrid pattern with two bands (105/ 100). Hybrid progenies obtained from crosses between two homozygous $100 / 100$ and $76 / 76$ plants at SKDH-2, also produced two bands (100/76) indicating monomeric structure (Fig. $1 \mathrm{~B}, \mathrm{C})$. The monomeric behavior of SKDH allozymes in guayule conformed with that found in other species (Garvin et al., 1989; Tanksley and Rick, 1980). Since self-incompatibility prevented production of $\mathrm{F}_{2}$ generations through selfing, segregation analyses were based on the results from two crosses shown in Table 1. No significant differences were found between the observed and expected ratios, which indicated that SKDH at each zone is controlled by one locus.

Phosphoglucose isomerase. PGI showed four zones of activity designated PGI-1, PGI-2, PGI-3, and PGI-4. Allozymes of PGI-1 appeared to be variable. However, the genetic basis of PGI-1 was not addressed due to poor resolution of the allozymes. As in other species, PGI-1 allozymes maybe localized in plastids (Weeden, 1983; Weeden and Gottlieb, 1979). Five bands (representing alleles 121, 114, 106, 100, and 95) were observed at zone PGI-2 in different individuals. Hybrid individuals at PGI-2 showed a three-banded pattern, which suggests that PGI-2 enzymes are active as dimers (Figs. 1 and 2). The dimeric structure of PGI has also been demonstrated in tomato (Lycopersicon esculentum; Tanksley, 1980) and tepary bean (Phaseolus acutifolius; Garvin et al., 1989). Inheritance analyses indicated that the PGI-2 zone is coded by one locus (Table 1). Plants showed one, two, or three bands at PGI-3 zone. PGI4 zone was observed in some plants, but it was of a poor staining quality. Consequently, we did not characterize those two zones. The question remains whether the bands observed at PGI-3 are the product of intergenic cross dimerization or products of a separate locus. More research is needed to improve staining intensity of the PGI-4 zone before the inheritance of PGI at these two zones can be elucidated.

The genetic control of the isozyme variation that resulted from this study is valuable for identification of the zygotic and asexual progenies produced by facultative apomictic polyploid guayule plants. These markers may also be used to determine the degree of apomixis in different guayule genotypes. In addition, the potential association of these isozymes with traits of interest, such as rubber content and rubber quality, could provide for early screening of many plants at seedling stage, thus simplifying and speeding up the guayule improvement program.

\section{Literature Cited}

Ellstrand, N.C. 1984. Multiple paternity within the fruits of the wild radish, Raphanus sativus. Amer. Nat. 123:819-828.

Esau, K. 1944. Apomixes in guayule. Proc. Natl. Acad. Sci. 30:352355.

Estilai, A. 1984. Inheritance of flower color in guayule. Crop Sci. 24:760-762.

Estilai, A. 1986. Registration of Cal-6 and Cal-7 guayule germplasm. Crop Sci. 26:1261-1263.

Estilai, A., A. Hashemi, and J.G. Waines. 1990. Isozyme markers for cultivar identification-in guayule. HortScience 25 :346-348.

Garvin, D.F. 1987. The inheritance and linkage of isozyme genes in tepary bean. Phaseolus acutifolius A. Gray. MS Thesis, Univ. of California, Riverside.

Garvin, D.F., M.L. Roose, and J.G. Waines. 1989. Isozyme genetics and linkage in tepary bean Phaseolus acutifolius A. Gray. J. Hered. 80:373-376.

Gerstel, D.U. 1950. Self-incompatibility studies in guayule. II. Inheritance. Genetics 35:482-596.

Gerstel, D.U. and W. Mishanec. 1950. On the inheritance of apomixis in Parthenium argenatatum. Bot. Gaz. 112:96-106.

Hashemi, A., J.E. West, and J.G. Waines. 1986. Chromosome pairing and pollen fertility in interspecific hybrids of species of Parthenium (Asteraceae). Amer. J. Bot. 73:980-988.

Powers, L. 1945. Fertilization without reduction in guayule (Parthenium argentatum Gray) and a hypothesis as to the evolution of apomixis and polyploidy. Genetics 30:323-346.

Schloman, W.W., Jr. 1986. The utilization and economic impact of by-products derived from guayule. 6th Annu. Guayule Rubber Soc. Conf. Program and Summaries. College Station, Texas, 8-10 Oct. 1986.

Tanksley, S.D. 1980. PGI-1, a single gene in tomato responsible for a variable number of isozymes. Can. J. Genet. Cytol. 22:271-278.

Tanksley, S.D. and C.M. Rick. 1980. Isozymic gene linkage map of the tomato: Applications in genetics and breeding. Theor. Applied Genet. 57:161-170.

Tanksley, S.D., H. Medina-Filho, and C.M. Rick. 1982. Use of naturally-occurring enzyme variation to detect and map genes controlling quantitative traits in an interspecific backcross of tomato. Heredity 49:11-25.

Thompson, A.E. and D.T. Ray. 1989. Breeding guayule. Plant Breed. Rev. 6:93-165.

Tysdal, H.M., A. Estilai, I.A. Siddiqui, and P.F. Knowles. 1983. Registration of four guayule germplasms. Crop Sci. 23:189.

Weeden, N.F. 1983. Plastid isozymes, p. 139-156. In: S.D. Tanksley and T.I. Orton (eds.). Isozyme in plant genetics and breeding, Part A. Elsevier, New York.

Weeden, N.V. and L.D. Gottlieb. 1979. Distinguishing allozymes and isozymes of phosphoglucoisomerases by electrophoretic comparisons of pollen and somatic tissues. Biochem. Genet. 17:287-296.

Weeden, N.F., R. Provvidenti, and G.A. Marx. 1984. An isozyme marker for resistance to bean yellow mosaic virus in Pisum sativum. J. Hered. 75:411-412.

Weibull, P., L. Ghatnekar, I. Frykman, and B.O. Bengtsson. 1988. Electrophoretic variation in Festuca ovina L., p. 25-37. In: G. Ewertson and P. Weibull (eds.). Agrihortique Genetics. Ablandstryck, Landskrona, Sweden.

Zaiger, J.K., D.E. Soltis, and G.K. Brown. 1984. Electrophoretic evaluation of registered Parthenium argentatum germplasm Cal-3. El Guayulero 6(3):9-12. 